\title{
Melt Conditioned Direct Chill (MC-DC) Casting of AA-6111 Aluminium Alloy Formulated from Incinerator Bottom Ash (IBA)
}

\author{
Kawther W Al-Helal ${ }^{1, *}$, Jaime Lazaro-Nebreda ${ }^{1}{ }^{1}$, Jayesh B Patel ${ }^{1}$, Geoff M Scamans ${ }^{2}$ \\ and Zhongyun Fan ${ }^{1}$ \\ 1 Brunel Centre for Advanced Solidification Technology, Brunel University London, \\ Uxbridge, London UB8 3PH, UK \\ 2 Innoval Technology Limited, Beaumont Cl, Banbury OX16 1TQ, UK \\ * Correspondence: kawther.al-helal2@brunel.ac.uk
}

Received: 25 July 2019; Accepted: 26 August 2019; Published: 28 August 2019

\begin{abstract}
The melt conditioned direct chill (MC-DC) casting process has been used for the production of billets of AA-6111 alloy formulated from recycled aluminium derived from incinerator bottom ash (IBA). The billets were homogenised and then extruded into planks. Optical metallography of the MC-DC billets showed equiaxed refined grains in comparison to DC and grain refined (DC-GR) billets formulated from the same scrap source. Microstructure evaluation for the extruded planks showed a less extensive peripheral coarse grain (PCG) for the MC-DC sample.
\end{abstract}

Keywords: incinerator bottom ash; metal recycling; material recovery; melt conditioning; AA-6111 alloy

\section{Introduction}

Incineration of waste has been used for many years, and it has become a more and more popular process worldwide as an alternative to landfilling. The solid residue left from waste incineration is known as incinerator bottom ash (IBA). Technologies for processing the IBA have been developed and used for many years. These technologies have enabled various useful and valuable materials to be recovered, such as aluminium [1,2]. Waste-to-energy is a leading technology in Europe for the treatment of municipal solid waste. Annually, 80 million tons of municipal solid waste is treated in waste-to-energy plants, and this treatment generates around 78 million MWh of heat and 31 million MWh of electricity. The annual production of IBA in Europe is about 20 million tons, of which $25 \%$ is treated municipal solid waste [3,4].

Research activities on bottom ash treatment have been promoted in the past few years based on the need for reducing the losses of natural resources and because of the increasing cost of landfilling. This work has focused on the recovery of metal fractions and reuse of the non-metallic fraction in industries such as cement and road construction [5].

The recovery of aluminium and other elements from the incineration bottom ash is one of the most active topics in waste management. It has both economic and environmental benefit [6]. The production of secondary aluminium from recycled metal requires about $2.8 \mathrm{kWh} / \mathrm{kg}$ whilst the production of primary aluminium requires at least $45 \mathrm{kWh} / \mathrm{kg}$ [7]. The recovery processes of metals from incineration bottom ash include physical treatment to separate the fine size aggregates using screens, extraction of metals using magnetic and eddy current separators to separate ferrous from non-ferrous, leaching with water or chemical solvents to remove salts and soluble heavy metals, addition of Fe(III) or Al(III) salts, cements or any bonding agents to reduce the mobility of metal through washing, and sintering to immobilize heavy metals into an amorphous phase [5]. Due to the increased awareness on recovery of 
resources from bottom ash, developments have been made in both the physical and chemical separation techniques [1]. There are two types of treatment techniques: a dry process and a wet process. In the wet process, there are losses of aluminium recovery due to oxidation. The dry process that has been developed by Scanmetals $($ in Denmark has major advantages as it does not use water or chemicals. Furthermore, the technology makes it possible to recycle metals from aggregates down below $2 \mathrm{~mm}$ in size. The dry process involves x-ray scanners, compressed air, vibration and manual sorting.

The chemical composition of aluminium alloys formulated from recycled material is strictly related to the quality of the recovered aluminium. Recycled aluminium usually contains increased levels of impurities such as $\mathrm{Fe}$ and $\mathrm{Mn}$, compared to primary aluminium, so the alloy formulation can be more difficult to manage [8].

The production of semi-finished products starts with direct chill (DC) casting process, which produces billets or slabs for further processing such as rolling, extrusion or forging. The formation of coarse grain with non-uniform microstructure, chemical segregation, porosity and hot tearing are the most common problems encountered in direct chill casting. These defects can result in unacceptable mechanical properties of the final products [9]. Grain refinement by chemical inoculation is used extensively for the as-cast grain size control. In industry this is achieved by feeding a rod of grain refiner into a melt during DC casting. This is typically in the form of an Al-Ti-B master alloy [10]. Due to some disadvantages of chemical refinement like high cost, limitation of using grain refiner with cast alloys and interaction of grain refiner with present solutes, alternative methods such as electromagnetic stirring, ultrasonic cavitation and intensive melt shearing have been investigated [11].

For in-situ microstructural control and to overcome solidification defects, melt conditioned direct chill (MC-DC) casting technology has been developed at BCAST (Brunel Centre for Advanced Solidification Technology), and has been used for the production of industrial-scale billets by inserting a high shear rotor-stator device in the sump of the DC mould during the casting process [11]. The main advantages of high shear melt conditioning (HSMC) are the homogenisation of melt composition prior to the solidification, enhancement of both diffusion and chemical reaction processes within the melt, dispersion and fragmentation of oxide agglomerates and increased wettability of dispersed oxides. It has also been demonstrated that these dispersed oxide particles act as nucleation sites for grains and iron-containing intermetallics and the use of high shear melt processing can overcome the limitations of conventional casting processes [12]. Rotor-stator based shearing has been used successfully for the grain refinement, degassing, metal-matrix composite casting, and can be viewed as a multi-purpose device that can be used for any industrial casting processes from direct chill casting to twin roll casting [13]. The full description of the high shear melt conditioning process and refinement mechanisms have been reported elsewhere [14].

For the first time, the high shear melt conditioning process has been applied for the direct chill (DC) casting of an aluminium alloy formulated from the recovered aluminium fraction from incinerator bottom ash. Reusing recycled aluminium for the formulation of alloys for industrial applications in the UK provides both significant $\mathrm{CO}_{2}$ savings (less or no primary metal) and major cost savings.

\section{Experimental Procedures}

\subsection{Direct Chill Casting}

Milver Metals supplied $300 \mathrm{~kg}$ of their lion grade (DRYINC@ LION $+10 \mathrm{~mm}$ ) aluminium recovered from IBA. This metal was sourced from Scanmetals in Denmark. The lion grade aluminium was re-melted at BCAST and cast into ingots as shown in Figure 1. Alloy BA-6111 was formulated from 50\% bottom ash ingots and 50\% AA-6111 extrusion process scrap. The compositions of the lion grade (IBA), bottom ash ingot, standard AA-6111 and formulated BA-6111 alloy are given in Table 1. Al-Cu40 master alloy and pure Magnesium were added to adjust the copper and magnesium levels to match the target AA-6111 alloy. By using Thermos-Analyse machine IDECO TA 748CT, the liquidus temperature of the formulated BA-6111 was $\sim 921 \mathrm{~K}\left(648^{\circ} \mathrm{C}\right)$. 
Casting of BA-6111 alloy used a conventional single strand direct chill DC caster with a tilting furnace and launder/open-hot-top configuration. Billets of $152 \mathrm{~mm}$ in diameter and $\sim 2$ metre lengths were cast at $110 \mathrm{~mm} / \mathrm{min}$ with a constant water flow rate of 116 litres $/ \mathrm{min}$. For direct chill grain refined (DC-GR) casting, Al-5Ti-1B master alloy was added to the alloy melt in the launder prior to being poured into the DC casting system. The melt temperature in the launder was $963 \mathrm{~K}\left(690{ }^{\circ} \mathrm{C}\right)$. For melt conditioned direct chill (MC-DC), the high shear device was mounted on top of the hot-top and preheated to $\sim 700{ }^{\circ} \mathrm{C}$. After achieving steady-state casting at the speed of $110 \mathrm{~mm} / \mathrm{min}$, the high shear device was lowered into the melt and switched on to run at $\sim 2000 \mathrm{rpm}$. The position of the shearing device in the sump was electrically controlled. The position of the shearing device in the hot-top was placed at an appropriate depth.

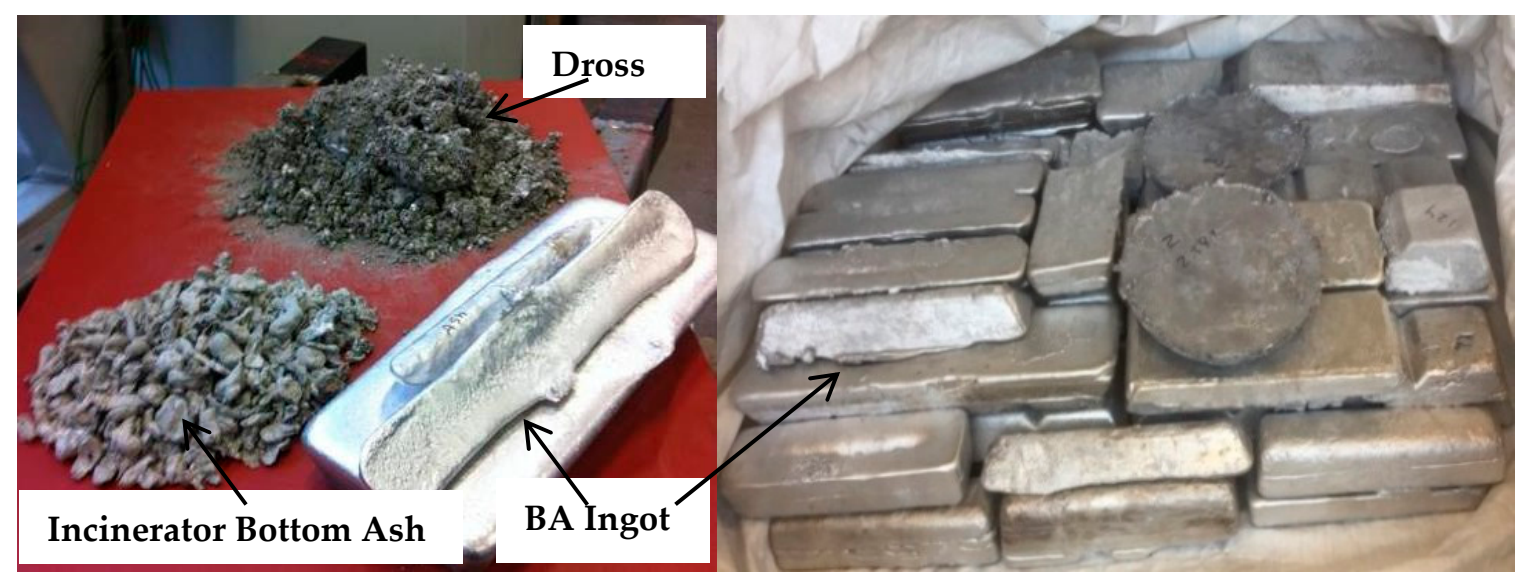

Figure 1. Incinerator bottom ash aggregates, bottom ash ingot and the dross left after crucible casting.

Table 1. Chemical composition of lion grade IBA, bottom ash ingot, standard AA-6111 and formulated BA-6111 alloys.

\begin{tabular}{ccccc}
\hline $\mathbf{W t} \%$ & Lion Grade IBA & Bottom Ash Ingot & Standard AA-6111 & Formulated BA-6111 \\
\hline $\mathrm{Si}$ & $1.5-2.5$ & 1.65 & 0.63 & 1.17 \\
$\mathrm{Fe}$ & $\sim 0.5$ & 0.48 & 0.25 & 0.36 \\
$\mathrm{Cu}$ & 0.7 & 0.41 & 0.75 & 0.76 \\
$\mathrm{Mn}$ & 0.3 & 0.31 & 0.20 & 0.39 \\
$\mathrm{Mg}$ & 0.03 & 0.07 & 0.75 & 0.75 \\
$\mathrm{Cr}$ & - & 0.03 & $<0.08$ & 0.05 \\
$\mathrm{Ni}$ & - & 0.02 & - & 0.02 \\
$\mathrm{Zn}$ & 0.6 & 0.41 & $<0.05$ & 0.26 \\
$\mathrm{Ti}$ & - & 0.02 & - & 0.03 \\
$\mathrm{~Pb}$ & - & 0.03 & - & 0.01 \\
$\mathrm{Sn}$ & - & 0.01 & Bal. & 0.01 \\
$\mathrm{Al}$ & $\mathrm{Bal}$ & Bal. & & Bal. \\
\hline
\end{tabular}

The DC, DC-GR and MC-DC billets of BA-6111 were cast successfully as shown in Figure 2a. Both the DC-GR and MC-DC billets were homogenized and extruded at a temperature of $480{ }^{\circ} \mathrm{C}$ and at a speed of $3 \mathrm{~m} / \mathrm{min}$ into flat bar $\sim 118 \times 4.8 \mathrm{~mm}$ as shown in Figure $2 \mathrm{~b}$. 


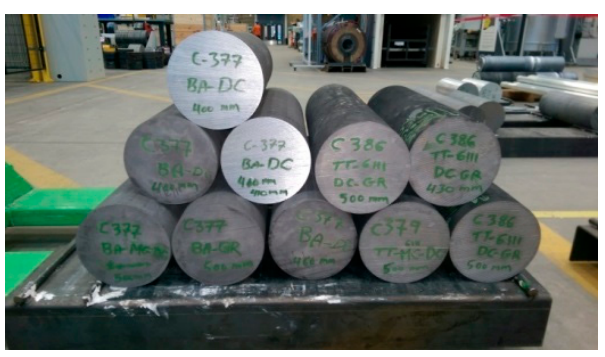

(a)

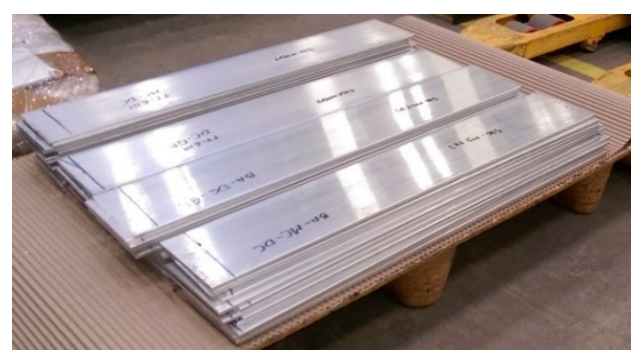

(b)

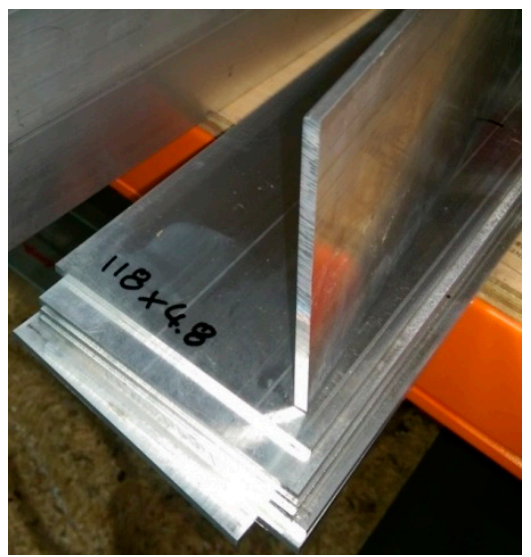

(c)

Figure 2. (a) Direct chill (DC), grain refined direct chill (DC-GR) and melt conditioned direct chill (MC-DC) billets, and $(\mathbf{b}, \mathbf{c})$ the extruded planks from DC, DC-GR and MC-DC of formulated BA-6111.

\subsection{Characterisation}

For metallographic characterisation, samples of longitudinal (RD) and transverse (TD) sections were mounted, ground, and polished down to a $0.04 \mu \mathrm{m}$ silica in water suspension. Anodization of polished samples was carried out at $20 \mathrm{~V}$ for $55 \mathrm{~s}$ in Barker's reagent to reveal the grain size and grain morphology. A Zeiss Axio-Vision optical microscope was used for this analysis on both the transverse and longitudinal cross-sections of the DC, DC-GR and MC-DC samples. The linear intercept method was used to measure the average grain size on polarized images.

For macrostructural analysis, samples were sectioned from the DC, DC-GR and MC-DC billets of the BA-6111 billets. These samples were macro-etched with Tucker's reagent to show the macrostructure and grain size across the sample.

\section{Results and Discussion}

\subsection{Aluminium Recovery}

According to Scanmetals specification sheet, the estimated yield for ingot casting for the DRYINCC LION $+10 \mathrm{~mm}$ is $82 \%-84 \%$. Due to the size limitation of melting process used at BCAST and the high levels of dross generated, the yield of the lion material was about $68 \%$ which is $14 \%-16 \%$ lower compared with that achieved by Milver using their furnace with EMP (electromagnetic pump) technology. The composition achieved of the BA-6111 has higher silicon and iron level than ideal for the AA-6111 alloy as shown in Table 1. The chemical composition of the dross collected from the bottom ash melt was mainly aluminium and silicon oxides, as shown in Figure 3.

In aluminium casting, the dross mainly consists of aluminium oxides, oxides of alloying elements such as $\mathrm{Si}, \mathrm{Fe}, \mathrm{Cu}, \mathrm{Mg}, \mathrm{Zn}$, etc. in addition to spinels, $\mathrm{AlN}, \mathrm{Al}_{4} \mathrm{C}_{3}$ and $\mathrm{AlP}$ [15]. The amount and composition of the dross depend on the source scrap mix and the type of melting furnace used for casting [16].

The most common procedure for dross treatment is to upgrade the aluminium content in the dross prior to melting. Mechanical grinding of the dross down to a coarse powder followed by screening 
with a 10 to 20 -mesh screen is the first step in this treatment. The concentrate (coarse size) typically contains $60 \%$ to $70 \%$ metallic aluminium and is melted, while the fine size fraction is sent to landfilled. This treatment will reduce the amount of dross smelted and lowering the amount of energy needed in the smelting operation.

\section{(Coupled TwoTheta/Theta)}

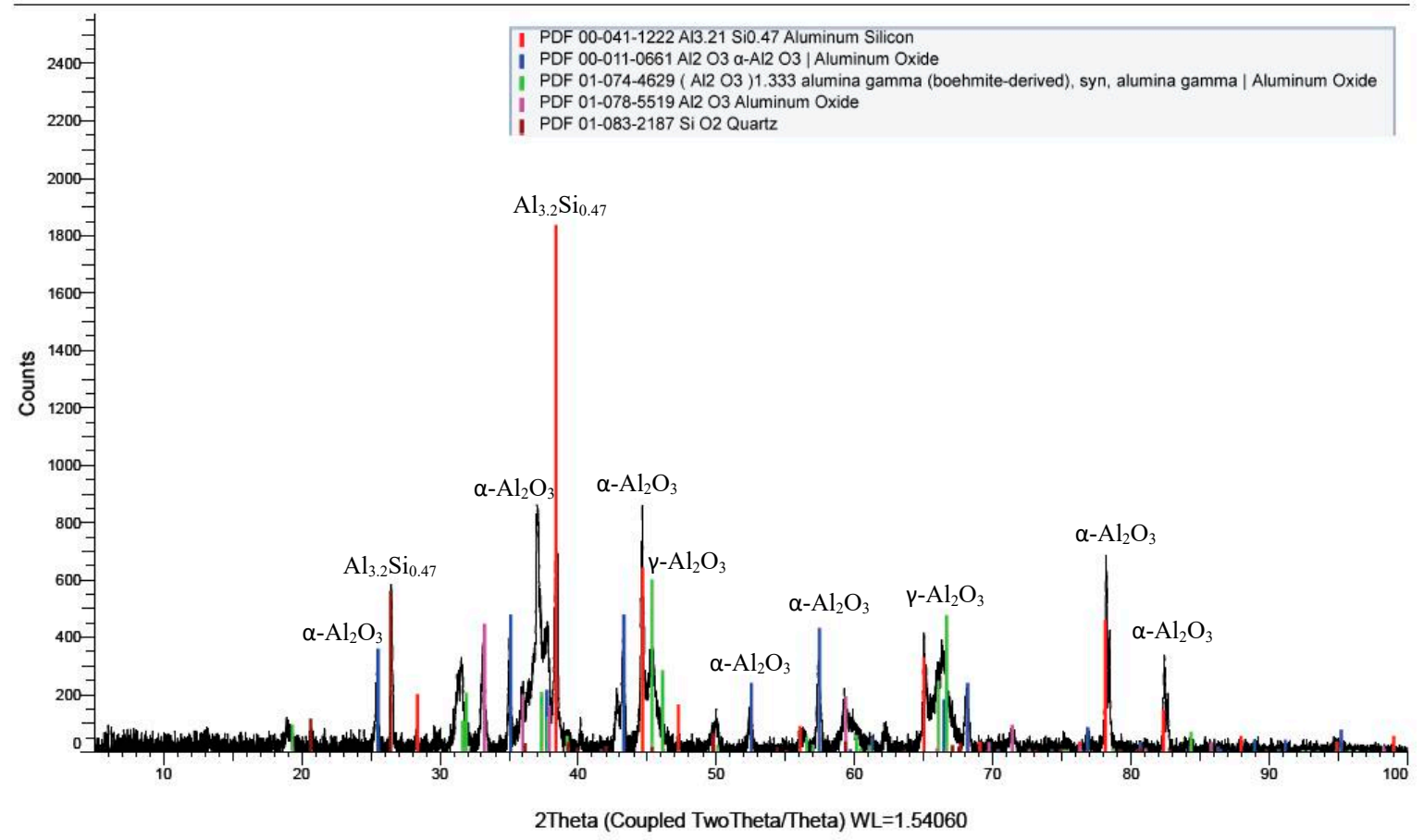

Figure 3. XRD of the dross left after ingot casting of incinerator bottom ash.

\subsection{Direct Chill casting}

Macro-etched samples of DC, DC-GR and MC-DC at the centre of the billets are shown in Figure 4. It is clear that a significant grain refinement was achieved by applying intensive melt conditioning in comparison to the DC and grain refined DC-GR billets of formulated BA-6111 alloy. During MC-DC casting, the physical effect of intensive melt shearing was more efficient than the chemical effect of Al-Ti-B grain refiner. All the sections showed no segregation or casting defect across the billets for DC, DC-GR and MC-DC casting.
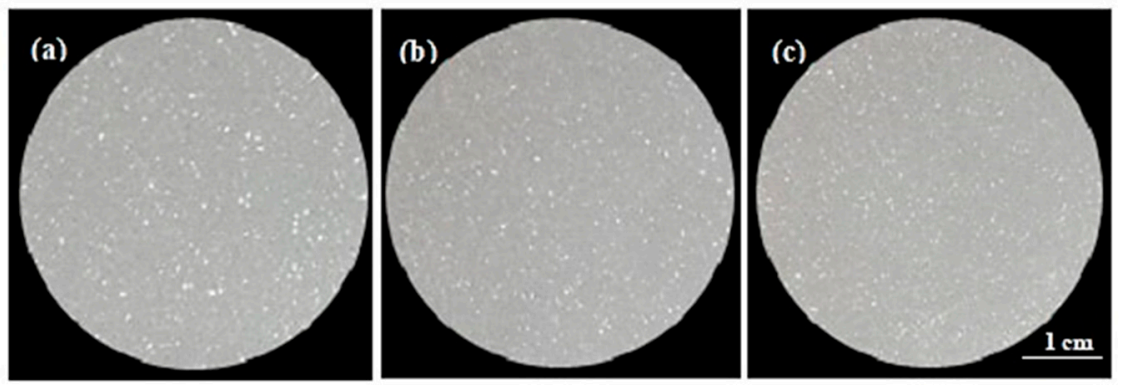

Figure 4. Macro-etched cross-sections from the bottom ash BA-6111 billets at the centre: (a) DC without GR, (b) DC with GR and (c) MC-DC without GR.

In conventional DC casting, it is well known that there is a non-uniform cooling rate across the cross-section which results in variation of grain size from the edge to the centre [17]. Applying intensive melt conditioning during MC-DC casting will enhance mass transfer and increase heat extraction 
rate in the sump. This leads to a uniform cooling rate across the cross-section and then a uniform microstructure in the billets.

Figure 5 shows the optical micrographs of direct chill (DC), grain refined direct chill (DC-GR) and melt conditioned direct chill (MC-DC) of formulated BA-6111 alloy. The microstructure of MC-DC, Figure $5 \mathrm{e}, \mathrm{f}$, showed equiaxed refined grains in comparison with DC, Figure $5 \mathrm{a}, \mathrm{b}$ and DC-GR, Figure $5 c, d$, billets. The average grain size across the billet section for DC, DC-GR and MC-DC were $362 \pm 32 \mu \mathrm{m}, 231 \pm 16 \mu \mathrm{m}$ and $220 \pm 10 \mu \mathrm{m}$, respectively.

Normally, in conventional DC casting (no grain refiner), large elongated columnar grains is formed across the billet but with the addition of grain refiner, the grain structure is equiaxed refined grains. Due to the composition of melt and the presence of grain refiner in the recycled source material from original casting, the grains were equiaxed for the conventional DC casting Figure 5a,b.
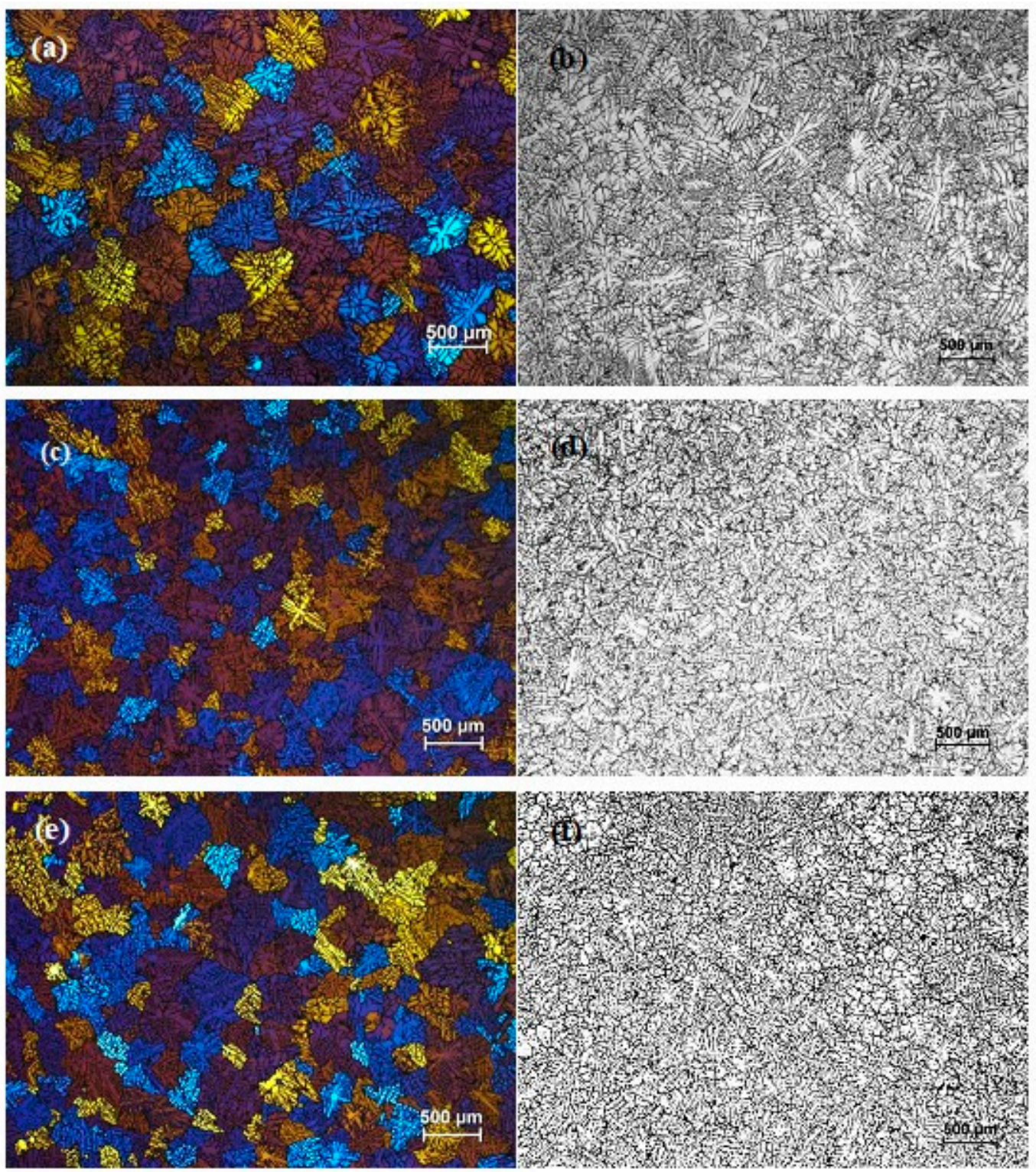

Figure 5. Optical micrographs of direct chill cast billets of bottom ash BA-6111, samples were sectioned from the central portion of DC, DC-GR and MC-DC cast billets. $(\mathbf{a}, \mathbf{b})$ DC without GR, (c,d) DC with GR, and (e,f) MC-DC without GR.

The position and shearing speed of the rotor-stator device can affect the size and morphology of the grains and grain size distribution across the casting section. Shearing at a relatively high speed 
or deep in the sump can develop rosette-like grains at the centre, whilst casting at lower speed and optimized position gives fine equiaxed dendritic grains with fine dendritic arm spacing across the whole section.

\subsection{Extrusion Planks}

Figure 6 shows the optical micrographs for sections prepared metallographically from the BA-6111 extruded planks. The microstructure of the extruded planks showed an un-recrystallized fibrous structure core with some peripheral coarse grain (PCG) especially for the MC-DC sample as shown in Figure $6 c, d$.
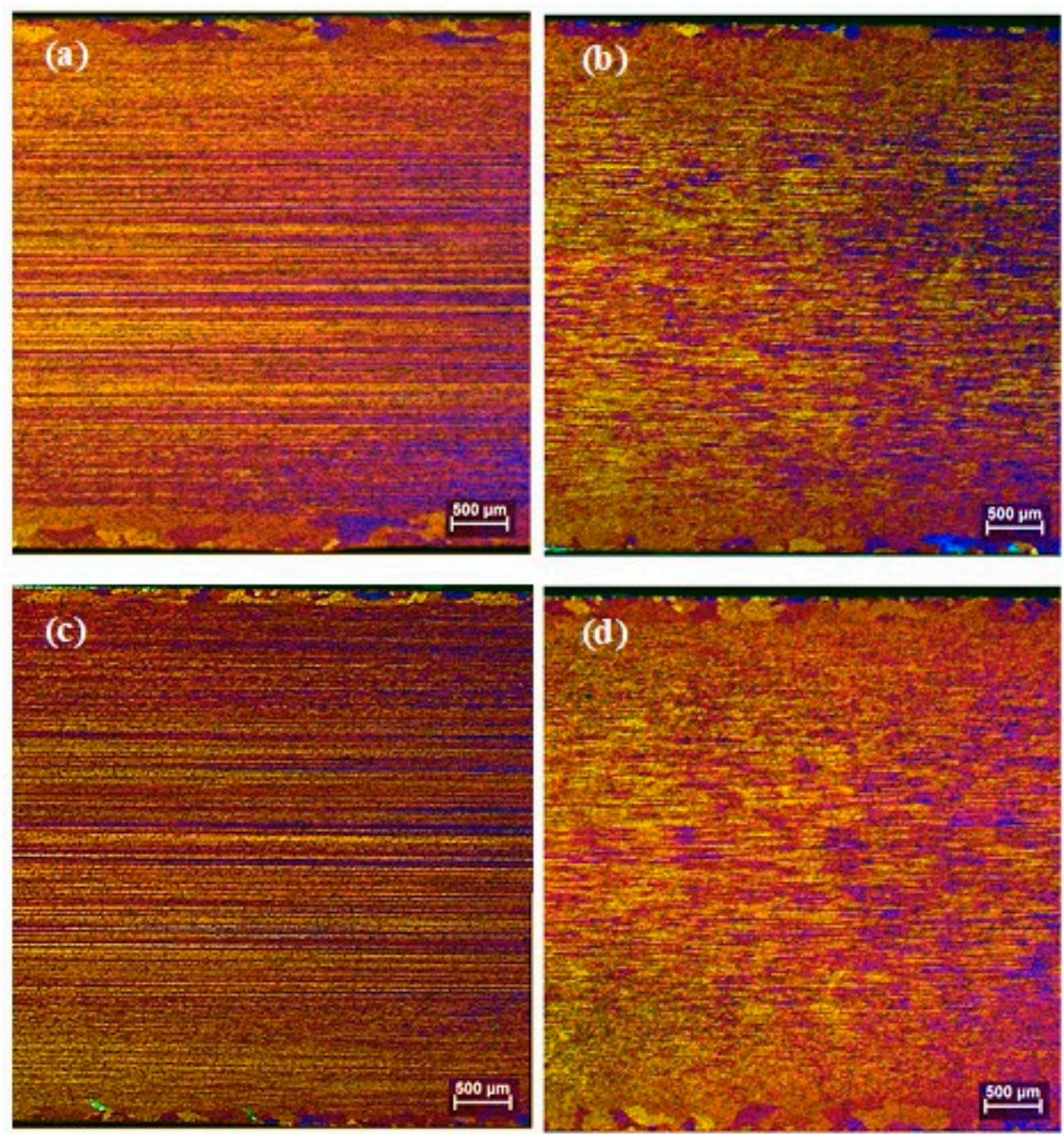

Figure 6. Optical micrographs of formulated BA-6111 planks extruded from, (a,b) DC-GR in longitudinal and transverse sections, and (c,d) MC-DC in longitudinal and transverse sections.

The PCG is a coarse-grained layer of recrystallized material occurring in the outer band of an extruded cross-section [18]. PCG is a detrimental product feature as it can impair good properties such as strength, corrosion resistance, ductility and toughness and it is desirable to minimise the PCG thickness. Peripheral recrystallization is due to a complex interplay of billet microstructure, alloy composition, presence of grain growth inhibitors such as $\mathrm{Mn}, \mathrm{Zr}$ and $\mathrm{Cr}$, extrusion conditions (temperature and speed) and finally the alloy critical temperatures, i.e., solvus, solidus and recrystallization [19]. 
The mechanical properties of as extruded planks and after thermo-mechanical treatment such as cold rolling with heat treatment were tested and the results will be reported in our next publication.

\section{Conclusions}

The BA-6111 alloy formulated from aluminium recovered from IBA was successfully cast into billets and extruded into thin planks without any casting defect. Applying melt conditioning in direct chill casting enhanced the microstructure of billets and extruded planks and increased impurity tolerance. The optical micrographs of MC-DC billets showed equiaxed refined grains in comparison with DC and grain refined DC-GR billets of the formulated BA-6111 alloy with no casting defects for all casting conditions. Microstructural evaluation for extruded planks of formulated bottom ash BA-61111 showed fibrous structure with less extensive peripheral coarse grain (PCG), especially for the melt conditioned direct chill (MC-DC) sample.

Author Contributions: K.W.A. drafted the manuscript and performed the experiments with J.B.P. and J.L.-N.; G.M.S. and Z.F. performed the data analyses and revised the manuscript.

Funding: This research was funded by the Innovate UK. Financial support from the 'Recycling of Aluminium through Innovative Technology' (REALITY) Project No. 102797 led by Jaguar Land Rover (JLR).

Acknowledgments: This work was carried out at BCAST, Brunel University London within the AMCC facility. Financial support from the 'Recycling of Aluminium through Innovative Technology' (REALITY) Project No. 102797 led by Jaguar Land Rover (JLR) and funded by Innovate UK, is gratefully acknowledged.

Conflicts of Interest: The authors declare no conflict of interest.

\section{References}

1. Kahle, K.; Bettina, K.; Jens, K.; Edmund, F.; Frans, L.; Lars, J.; Jakob, S. Bottom Ash from WtE Plants-Metal Recovery and Utilization; IWS: London, UK, 2015.

2. Hu, Y.; Bakker, M.C.M.; de Heij, P.G. Recovery and distribution of incinerated aluminum packaging waste. Waste Manag. 2011, 31, 2422-2430. [CrossRef] [PubMed]

3. Šyc, M.; Krausová, A.; Kameníková, P.; Šomplák, R.; Pavlas, M.; Zach, B.; Pohořelý, M.; Svoboda, K.; Punčocháŕ, M. Material analysis of Bottom ash from waste-to-energy plants. Waste Manag. 2018, 73, 360-366. [CrossRef] [PubMed]

4. Lamers, F. Tratment of bottom ashes of waste to energy installations: State of the art. In Waste management: Wasteto-energy; TK Verlag Karl Thomé-Kozmiensky: Dorfstraße, Germany, 2014; pp. 271-290.

5. Biganzoli, L.; Gorla, L.; Nessi, S.; Grosso, M. Volatilisation and oxidation of aluminium scraps fed into incineration furnaces. Waste Manag. 2012, 32, 2266-2272. [CrossRef] [PubMed]

6. Biganzoli, L.; Grosso, M. Aluminium recovery from waste incineration bottom ash, andits oxidation level. Waste Manag. Res. 2013, 31, 954-959. [CrossRef] [PubMed]

7. Das, S.K. Designing Aluminium alloys for a recycling friendly world. Mater. Sci. Forum 2006, 519, 1239-1244. [CrossRef]

8. Capuzzi, S.; Timelli, G. Preparation and melting of scrap in Aluminum recycling: A Review. Metals 2018, 8, 249. [CrossRef]

9. Eskin, D.G. Physical Metallurgy of Direct Casting of Aluminium Alloys; CRC Press: Thunder Bay, Canada; Taylor and Francis Group: Abingdon, UK, 2008.

10. McCartney, D.G. Grain refining of aluminium and its alloys using inoculants. AU Int. Mater. Rev. 1989, 34, 247-260. [CrossRef]

11. Li, H.-T.; Zhao, P.; Yang, R.; Patel, J.B.; Chen, X.; Fan, Z. Grain refinement and improvement of solidification defects in direct-chill cast billets of A4032 alloy by melt conditioning. Metall. Mater. Trans. B 2017, 48, 2481-2492. [CrossRef]

12. Al-Helal, K.; Chang, I.; Patel, J.B.; Fan, Z. Thermomechanical treatment of high-shear melt-conditioned twin-roll cast strip of recycled AA5754 alloy. JOM 2019, 71, 2018-2024. [CrossRef]

13. Patel, J.B.; Yang, X.; Mendis, C.L.; Fan, Z. Melt conditioning of light metals by application of high shear for improved microstructure and defect control. JOM 2017, 69, 1071-1076. [CrossRef] 
14. Patel, J.B.; Li, H.T.; Xia, M.X.; Jones, S.; Kumar, S.; O’Reilly, K.; Fan, Z. Melt conditioned direct chill casting (MC-DC) process for production of high quality Aluminium alloy billets. Mater. Sci. Forum 2014, 794, 149-154. [CrossRef]

15. Tsakiridis, P.E. Aluminium salt slag characterization and utilization-A review. J. Hazard. Mater. 2012, 217, 1-10. [CrossRef] [PubMed]

16. Hwang, J.Y.; Huang, X.; Xu, Z. Recovery of metals from Aluminum dross and saltcake. J. Min. Mater. Charact. Eng. 2006, 5, 47-62. [CrossRef]

17. Nadella, R.; Eskin, D.G.; Du, Q.; Katgerman, L. Macrosegregation in direct-chill casting of aluminium alloys. Prog. Mater. Sci. 2008, 53, 421-480. [CrossRef]

18. Harris, C.; Li, Q.; Jolly, M.R. Prediction of extruded microstructures using experimental and numerical modelling techniques. In Proceedings of the Aluminium Two Thousand, 5th World Congress, Rome, Italy, 18-22 March 2003; pp. 18-22.

19. Sheppard, P.T. Extrusion of Aluminium Alloys; Springer-Science and Business Media, B.V.: Berlin, Germany, 1999.

(C) 2019 by the authors. Licensee MDPI, Basel, Switzerland. This article is an open access article distributed under the terms and conditions of the Creative Commons Attribution (CC BY) license (http://creativecommons.org/licenses/by/4.0/). 